Cahiers « Mondes anciens »

MONDES

ANCIENS

Histoire et anthropologie des mondes anciens

$8 \mid 2016$

Montrer, démontrer

\title{
Démontrer sa légitimité : le lien dynastique dans les monnaies sévèriennes
}

Coining legitimacy: imperial bloodline and numismatic propaganda under the Severan dynasty

\section{Vincent N'Guyen-Van}

\section{(2) OpenEdition}

Journals

Édition électronique

URL : http://journals.openedition.org/mondesanciens/1636

DOI : 10.4000/mondesanciens.1636

ISSN : 2107-0199

Éditeur

UMR 8210 Anthropologie et Histoire des Mondes Antiques

Référence électronique

Vincent N'Guyen-Van, "Démontrer sa légitimité : le lien dynastique dans les monnaies sévèriennes », Cahiers « Mondes anciens » [En ligne], 8| 2016, mis en ligne le 21 juin 2016, consulté le 02 mai 2019. URL : http://journals.openedition.org/mondesanciens/1636; DOI : 10.4000/mondesanciens.1636

Ce document a été généré automatiquement le 2 mai 2019.

\section{c) (1) $(9)$}

Les Cahiers «Mondes Anciens » sont mis à disposition selon les termes de la licence Creative Commons Attribution - Pas d'Utilisation Commerciale - Pas de Modification 4.0 International. 


\title{
Démontrer sa légitimité : le lien dynastique dans les monnaies sévèriennes
}

\author{
Coining legitimacy: imperial bloodline and numismatic propaganda under the \\ Severan dynasty
}

Vincent N'Guyen-Van

Hic domus Aeneae cunctis dominabitur oris et nati natorum et qui nascentur ab illis. La maison d'Énée y dominera sur tous les pays, et les fils de ses fils et ceux qui naîtront d'eux. Virgile, Énéide, III, $97-98$ (trad. A. Bellessort, 1964). Loin d'accéder à cette responsabilité de l'extérieur, comme les empereurs qui, avant moi, se sont glorifiés d'avoir conquis leur fonction, je suis le seul à être né dans une demeure impériale. Les langes qui me reçurent ne furent pas communs : dès que je sortis du ventre maternel, ce fut la pourpre impériale qui m'accueillit, et le soleil me vit simultanément homme et empereur ${ }^{1}$.

C'est ainsi que, selon Hérodien, Commode s'adresse aux soldats lors de son avènement. Premier des empereurs porphyrogénètes, il appuie, dès le début, son règne sur la noblesse de sa naissance ${ }^{2}$. La nobilitas, comprise comme l'excellence lignagère, s'ajoute donc à la liste des onze vertus ${ }^{3} \mathrm{du}$ prince et la continuité légale de l'adoption impériale se renforce d'une exigence de continuité familiale. Successeurs des Antonins, les Sévères adoptent ce mode de légitimation dynastique bien que Septime Sévère soit précisément un de ces empereurs qui ont « conquis leur fonction ».

2 De retour à Rome après sa campagne contre Pescennius Niger et les royaumes d'outreEuphrate, Septime Sévère se déclare fils de Marc Aurèle ${ }^{4}$ et frère de Commode ${ }^{5}$. La seule réaction notable du Sénat face à cette fiction généalogique est celle de Pollenius Auspex qui félicite l'empereur de s'être enfin trouvé un père ${ }^{6}$. C'est donc sans heurt que Septime Sévère ajoute la mention divi Marci filius à sa titulature et que son fils prend les noms de Marcus Aurelius Antoninus sous lesquels il est connu de ses contemporains. Cette 
adoption posthume s'accomplit en même temps que le jeune Caracalla reçoit le titre de César. Elle participe de fait à l'installation de la famille sévérienne sur le trône ${ }^{7}$. On trouve, parmi les sénateurs de l'époque, des gendres ${ }^{8}$ et petit-fils de Marc Aurèle. La fiction dynastique sévérienne n'est donc pas destinée à tromper les sénateurs, mais à servir la propagande du nouveau régime.

La notion de propagande, appliquée à l'empire romain, a pu être contestée9. Le Prince, en effet, n'a pas à manipuler une opinion publique impuissante ${ }^{10}$ pour obtenir le pouvoir en droit, mais à montrer, par sa magnificence, qu'il le détient en fait. Il n'en reste pas moins que le pouvoir impérial cherche à construire sa propre image et à la diffuser auprès de ses sujets en multipliant les supports textuels et iconographiques ${ }^{11}$. Cette dissémination d'un message impérial, quelle que soit son efficacité ${ }^{12}$, vise à propager des idées ${ }^{13}$ et peut donc être considérée comme une forme de propagande ${ }^{14}$. Qui plus est, avec la chute d'une dynastie, il faut qu'une famille, une gens, en remplace une autre avec l'accord, sincère ou contraint, de l'armée et du Sénat ${ }^{15}$. Or, pendant les périodes de guerres civiles, l'adhésion des acteurs politiques romains à un nouveau pouvoir ne va pas de soi ${ }^{16}$. La loyauté des soldats est, ici, l'élément déterminant et, malgré l'opinion que l'historiographie sénatoriale a de Commode, cette loyauté reste avant tout dynastique ${ }^{17}$. En outre, l'accession au pouvoir par les armes impose à Septime Sévère et sa famille de rétablir la fiction du consensus politique ${ }^{18}$. Honteuse par essence, la guerre civile ne peut en effet servir à légitimer le pouvoir sévérien ${ }^{19}$. Il faut que les Sévères convainquent les soldats, le sénat et le peuple de Rome que leur pouvoir repose sur bien plus que le soutien ponctuel d'une partie de l'armée ${ }^{20}$. Ils cherchent dès lors à influencer ces acteurs politiques en diffusant un ensemble d'idées et de messages au moyen, entre autres, de leur monnayage. La fiction généalogique qui fait de Septime Sévère un Antonin n'a pas d'autre but.

Elle s'inscrit du reste dans une tradition aristocratique bien ancrée à Rome. Acilius Glabrio, auquel on propose l'empire en 192, est considéré comme le plus noble des sénateurs car il descend d'Énée et a exercé deux fois le consulat ${ }^{21}$. Si ses contemporains prétendent descendre du prince troyen, rien n'empêche Septime Sévère d'être le fils du divin $\operatorname{Marc}^{22}$. Pertinax, lors de son accession au pouvoir impérial, avait déjà dû mettre en scène un consentement antonin en s'entourant de Claudius Pompeianus ${ }^{23}$ et du même Acilius Glabrio, respectivement gendre et parent de Marc Aurèle. En outre, deux des adversaires de Septime Sévère, Didius Julianus et Clodius Albinus sont apparentés à Marc Aurèle et $\mathrm{Commode}^{24}$. Or les premières frappes du règne de Septime Sévère ont lieu dès juin 193, alors que Didius Julianus et Clodius Albinus sont tous deux candidats à l'empire ${ }^{25}$ . Le rattachement factice des Sévères aux Antonins s'inscrit donc dans le cadre de cette concurrence généalogique liée à la guerre civile ${ }^{26}$. Le précédent imposé par Commode interdit d'accéder à l'empire sans mettre en avant sa nobilitas. Pour être empereur il faut désormais être un Antonin en plus d'être un César. La question n'est donc plus de savoir si les acteurs politiques de la période sont dupes de cette fiction généalogique, puisque Septime Sévère ne peut pas en faire l'économie.

Plus que les motivations politiques du rattachement des Sévères aux Antonins, c'est donc leur modus operandi qui doit retenir notre attention. La construction de cette fiction transparente est en effet un processus qui court sur toute la période et domine la propagande impériale. Elle se met en place dans l'onomastique des empereurs et dans les titulatures de la famille impériale. Elle se donne à voir dans des cérémonies officielles et dans des récits soigneusement construits. À travers leur production iconographique, les Sévères se mettent en scène et donnent à voir un élément théoriquement invisible de 
l'idéologie impériale : la continuité dynastique. Or c'est dans la numismatique impériale que cette propagande iconographique s'exprime avec le plus d'efficacitée ${ }^{27}$. Supports d'images et de textes, les monnaies circulent à travers l'Empire avec une fluidité que les inscriptions monumentales et la statuaire ne peuvent égaler ${ }^{28}$. Les contraintes matérielles qui pèsent sur la frappe monétaire imposent de concentrer le discours politique, de le réduire à ses expressions les plus efficaces. Le système de communication iconographique des monnaies est de fait très limité, mais sa clarté s'en trouve renforcée. Les monnaies permettent la communication d'éléments d'un discours officiel immédiatement intelligibles ${ }^{29}$ pour la vaste majorité de la population ${ }^{30}$ à laquelle, précisément, est destinée la fiction généalogique sévérienne. En outre, leur production rapide et massive permet la diffusion d'un message riche ${ }^{31}$ et nuancé, continuellement adapté aux volontés du pouvoir. Parce qu'elles visent à inscrire les empereurs successifs dans une continuité qui est elle-même une création politique, ces monnaies permettent d'étudier comment l'idée d'une dynastie antonine renouvelée est construite pour légitimer les règnes des premiers Sévères.

6 L'accession au trône de Septime Sévère passe par son rattachement personnel à ses prédécesseurs. Il adopte donc le nom de Pertinax dont il se présente comme le justicier et, une fois Didius Julianus mort et les cohortes prétoriennes dispersées, il rajoute l'épithète Pius à sa titulature ${ }^{32}$. Afin de montrer aux Romains son attachement à la mémoire de Pertinax, Septime Sévère ordonne qu'une image dorée de Pertinax soit portée dans le Cirque sur un char tiré par des éléphants ${ }^{33}$. Cette fidélité à la mémoire de Pertinax sert avant tout à rassurer le Sénat quant aux intentions de Septime Sévère à son égard. À l'inverse, le choix du rattachement à Marc Aurèle et Commode vise à contenter les soldats et à rassurer la population quant à la stabilité du régime impérial. Septime Sévère impose la divinisation de Commode, dont la mémoire avait été condamnée par le Sénat ${ }^{34}$.

Fig. 1 : Septime Sévère, aureus, 193-194 ap. J.-C.
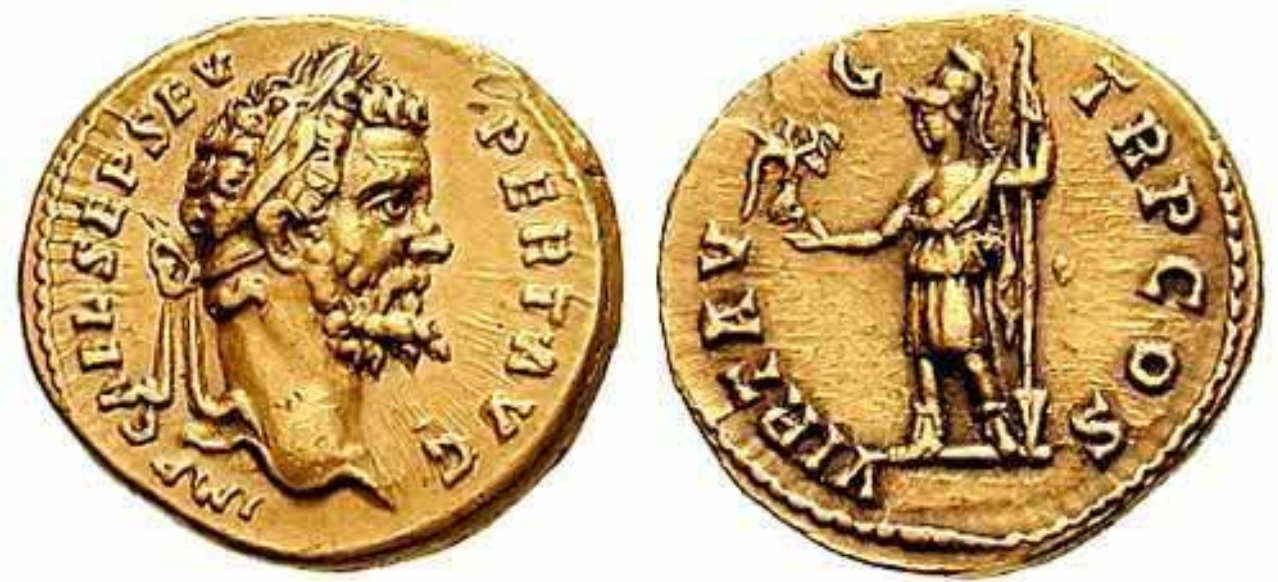

RIC, Severus, p. 95, 24. Droit : Buste lauré. IMP CAES L SEPT SEV PERT AVG. Revers : Virtus tenant une lance et la Victoire. TR P COS VIRT AVG.

CoinArchives 
Fig. 2 : Septime Sévère, aureus, 198-200 ap. J.-C.
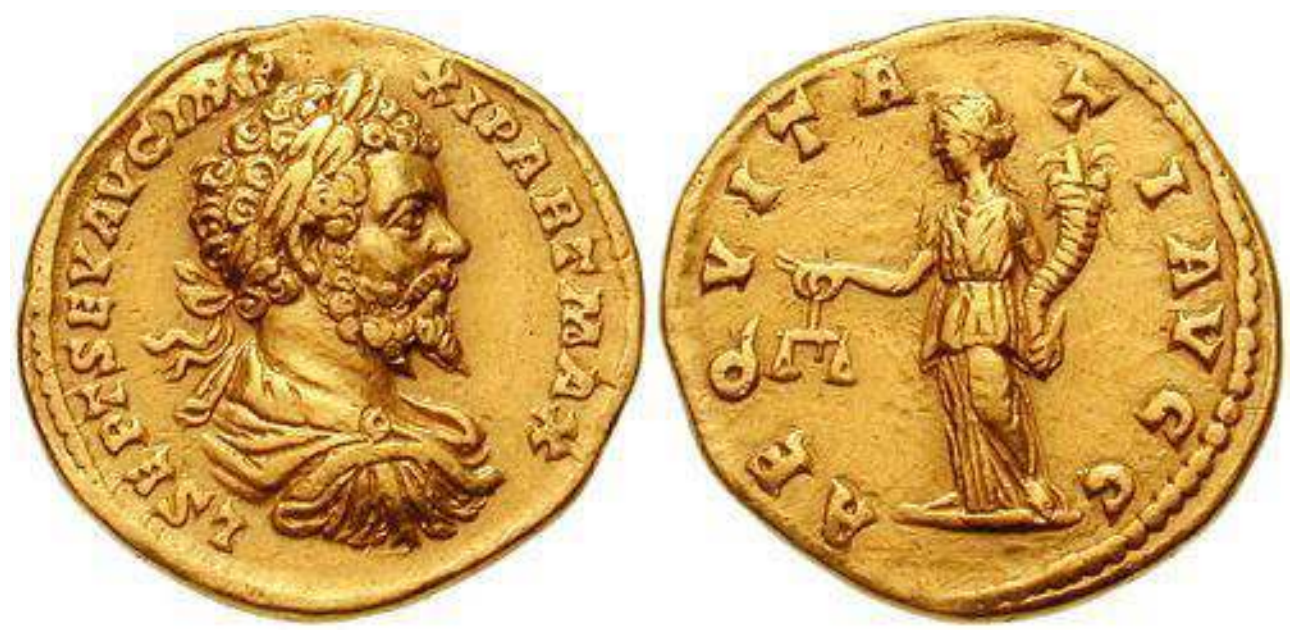

RIC, Severus, p. 105, 122a. Droit : Buste drapé, cuirassé et lauré. L SEPT SEV AVG IMP XI PART MAX. Revers : Aequitas debout, drapée, portant une balance dans la main droite et une corne d'abondance dans la main gauche.

CoinArchives

7 Plus que la fraternité de Commode, c'est la paternité de Marc Aurèle que Septime Sévère recherche ${ }^{35}$ et c'est le nom de ce dernier que prend Caracalla, comme le souligne Hérodien (III, 10, 5) : «L'âné, qui, avant d'appartenir à la famille impériale, avait pour vrai nom Bassianus, avait reçu de Sévère, après que ce dernier eut réussi à obtenir la dignité suprême, celui d'Antoninus, car son père voulait qu'il portât le nom de Marc Aurèle. » Septime Sévère adopte donc, dans ses monnaies, médailles et statues, un type de portrait que les spécialistes appellent «type de l'adoption ${ }^{36}$ ». Les monnaies sévériennes abandonnent donc le portrait militaire des premiers temps du règne, au front plissé et à la mâchoire très accusée, au profit d'un visage apaisé, encadré de cheveux bouclés et allongé par sa barbe ${ }^{37}$ rappelant les portraits ${ }^{38}$ et monnaies ${ }^{39}$ de Marc Aurèle (fig. 1-2). Le regard droit du chef de guerre est remplacé par l'air songeur du philosophe. Cette évolution peut ne pas être limitée aux représentations de Septime Sévère car celui-ci peut avoir cultivé, dans son apparence, une ressemblance avec Marc Aurèle. Si le fait n'est pas attesté pour Septime Sévère, on sait que Macrin, devenu empereur, se laisse pousser la barbe pour cette raison précise. Hérodien $(\mathrm{V}, 2,3-4)$ nous dit en effet de lui que, demeuré à Antioche, « il y soignait sa barbe, marchait plus doucement que nécessaire, répondait à qui venait le voir avec une infinie lenteur et de la difficulté, au point que souvent on ne l'entendait même pas parce qu'il baissait la voix. En prenant ces attitudes, il cherchait à imiter les manières de Marc Aurèle ». À la même période, Caracalla, le nouveau Marcus Aurelius, apparait sur des monnaies ${ }^{40}$ dans des portraits qui rappellent ceux du jeune Commode ${ }^{41}$. La référence iconographique aux derniers Antonins se poursuit durant le règne de Caracalla. Le médaillon dit d'Aboukir ${ }^{42}$ représente Caracalla portant un bouclier et une lance. Cette iconographie, traditionnellement rapprochée de l'alexandromanie supposée de Caracalla, est en fait reprise des médaillons de Marc Aurèle, Commode et Septime Sévère ${ }^{43}$. Des thèmes iconographiques considérés comme typiques du règne de Caracalla sont donc, eux aussi, issus du vocabulaire antonin.

8 La juxtaposition entre les familles de Marc Aurèle et de Septime Sévère passe également par l'élaboration d'un discours rapprochant leurs épouses, Faustine la Jeune et Julia 
Domna respectivement ${ }^{44}$. Comme son mari et son fils, Julia Domna développe une iconographie antonine et ses monnaies ${ }^{45}$ imitent, autant que faire se peut, celles de Faustine $^{46}$. Si la ressemblance physique des deux impératrices est limitée, Julia Domna adopte une titulature calquée sur celle de Faustine la Jeune. La première partie du règne de Septime Sévère concentre donc sa propagande sur le lien généalogique fictif entre Antonins et Sévères. Le volet numismatique de cette propagande montre que l'image même des premiers Sévères est manipulée pour se rapprocher de celle de la dynastie précédente. Or la ressemblance physique ainsi mise en avant, pour contrainte qu'elle soit, est la seule preuve dont leurs contemporains peuvent disposer pour se convaincre du lien familial ici revendiqué. Une fois ses derniers adversaires vaincus et son règne bien assuré, Septime Sévère s'emploie à consolider la position de sa famille à la tête de l'État romain.

Fig. 3 : Septime Sévère, aureus, 202-210 ap. J.-C.
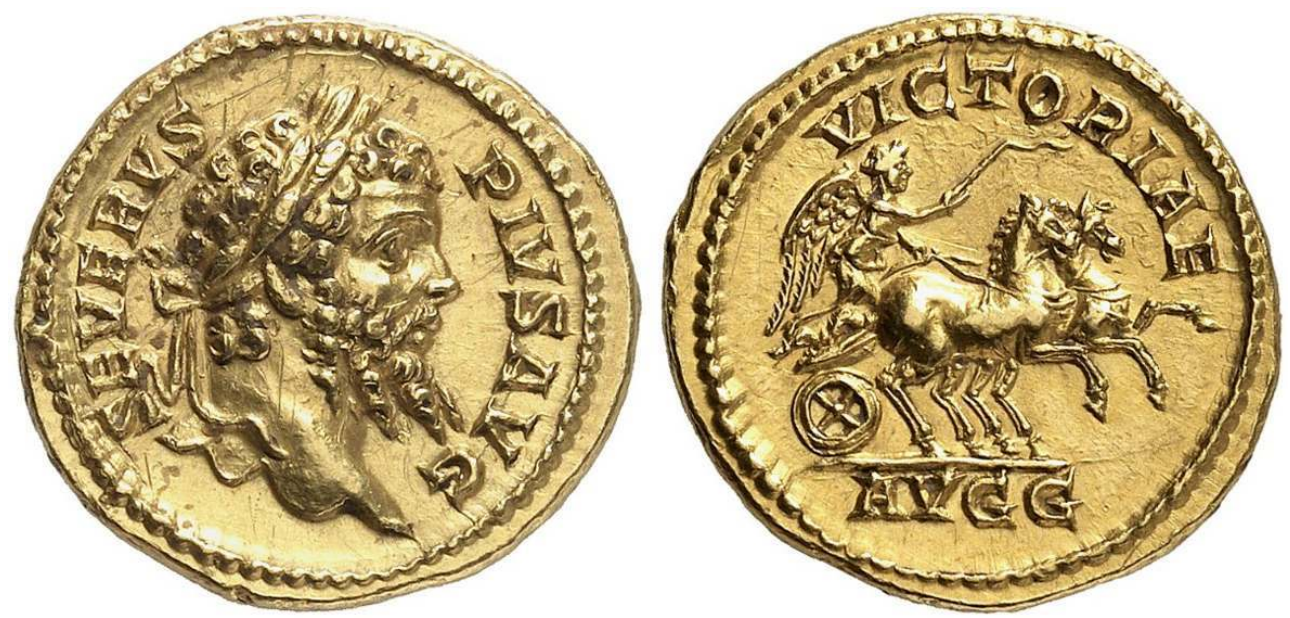

RIC, Severus, p. 128, 299. Droit : Buste lauré. SEVERUS PIVS AVG. Revers : Victoire consuisant un bige. VICTORIAE AVGG.

CoinArchives

9 À partir des années $200^{47}$, les portraits de Septime Sévère et Julia Domna s'éloignent de la norme antonine. Ceux de l'empereur adoptent le type dit “Sérapis ${ }^{48}$, caractérisé par une barbe abondante divisée en quatre (fig.3). De retour de leur voyage en Égypte ${ }^{49}$, les Sévères mettent ainsi en avant leur dévotion au dieu alexandrin ${ }^{50}$. Les portraits de l'impératrice affichent quant à eux des coiffures monumentales ${ }^{51}$, vraisemblablement des perruques à la mode syrienne ${ }^{52}$. Leur regard retrouve des expressions volontaires et abandonnent les yeux levés vers le ciel, synonymes de contemplation philosophique. Les monnaies mettent de plus en plus en avant les deux fils du couple impérial et c'est en tant que famille que les Sévères assurent désormais la prospérité. La bonne entente du couple impérial est garante d'une concordia aeterna ${ }^{53}$, qui relève avant tout de l'idéal philosophique ${ }^{54}$. Julia Domna et ses fils représentent la felicitas saeculi ${ }^{55}$ tandis que Caracalla et Géta, parce qu'ils promettent à l'Empire une succession paisible ${ }^{56}$, incarnent l' aeternitas imperii ${ }^{57}$. Aucun de ces thèmes n'est spécifiquement sévérien, cependant, et cette expression numismatique n'est que l'aboutissement d'une évolution entamée dès Auguste. 
Fig. 4 : Septime Sévère, aureus, 202-210 ap. J.-C.
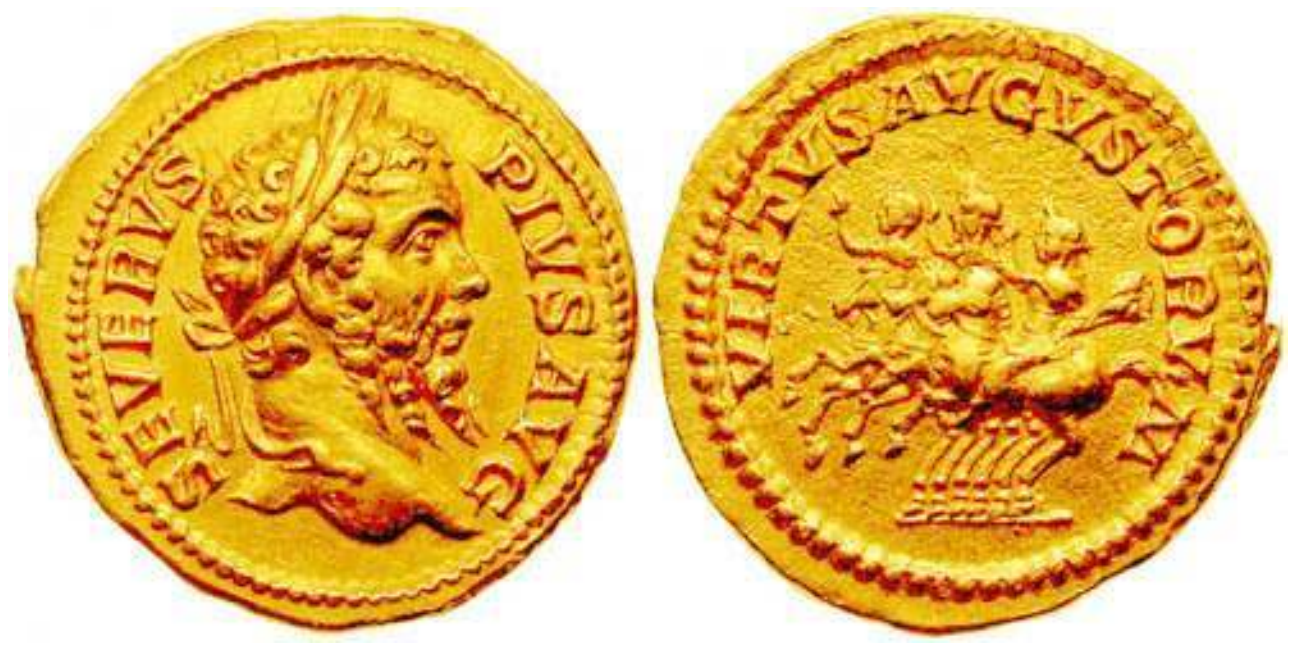

RIC, Severus, p. 129, 305. Droit : buste lauré. SEVERUS PIVS AVG. Revers : Septime Sévère, Caracalla et Géta à cheval, levant la main droite. VIRTVS AVGVSTORVM.

CoinArchives

Fig. 5a : Marc Aurèle, aureus, 173-174 ap. J.-C.
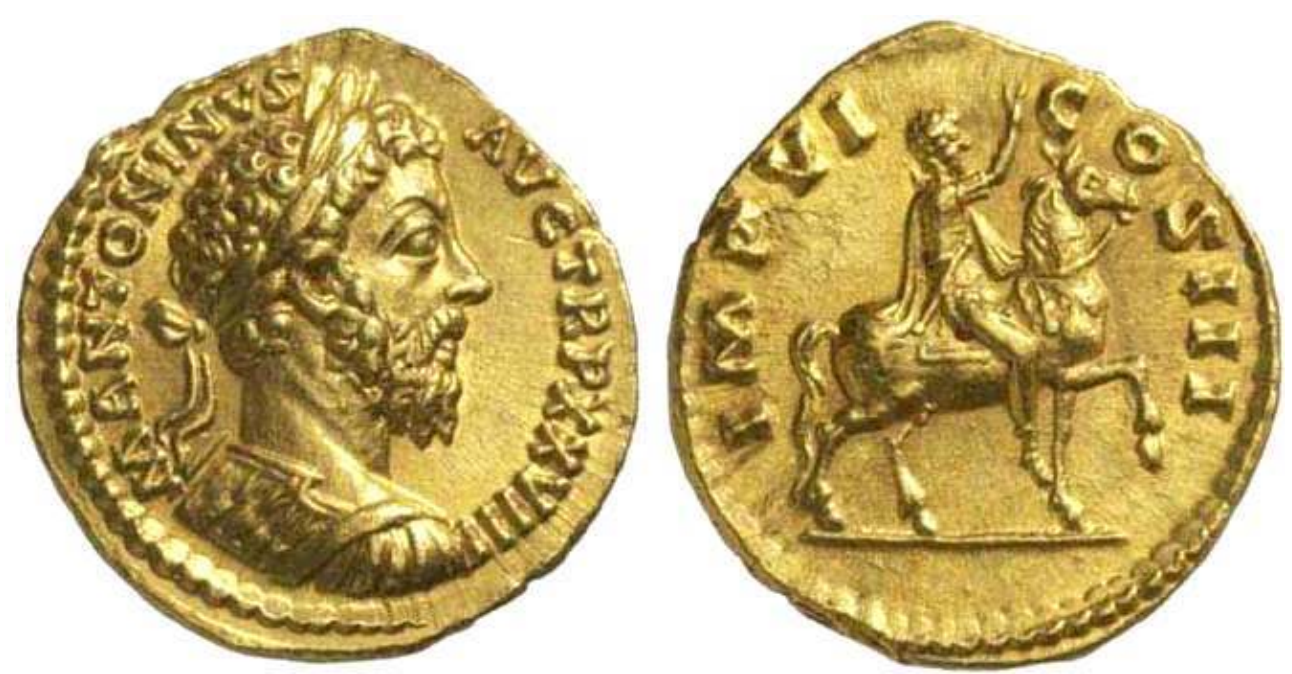

RIC, MarcusAurelius, p. 236, 295. Droit : buste cuirassé et lauré. M ANTONINVS AVG TR P XXVIII. Revers : Marc Aurèle en habit militaire, à cheval, levant la main droite et tenant un parazonium dans la main gauche.

10 La dynastie sévérienne est en revanche la première à se targuer de compter trois Augustes dont le monnayage met en avant la virtus. Sur un aureus de l'année 209, les trois empereurs sévériens chevauchent côte à côte et lèvent la main droite, dans un geste qui rappelle celui de la statue équestre de Marc Aurèle, reproduite elle aussi sur des aurei (fig. 4). On peut également rapprocher cette représentation des jeunes princes sévériens d'une monnaie figurant Commode à cheval, levant la main droite ${ }^{58}$ (fig. 5a). La mise en avant de la famille de Septime Sévère et la construction de son image dynastique s'appuient donc toujours sur une iconographie et des thèmes antonins, qu'elle modifie pour mieux servir son propos. La centralité de la famille impériale dans l'État romain permet de la présenter comme la pierre d'achoppement de la société impériale. De sa 
solidité et de sa continuité dépendent le bonheur de ses sujets. La domus impériale reçoit de fait les épithètes, Augusta, sacra et divina ${ }^{59}$ qui marque son lien ambigüe avec le divin ${ }^{60}$. L'aura religieuse qui entoure la personne du prince s'étend à ses fils, futurs Augustes, et à son épouse, l'Augusta.

Fig.5b : Iulia Domna, aureus, 196-211 ap. J.-C.
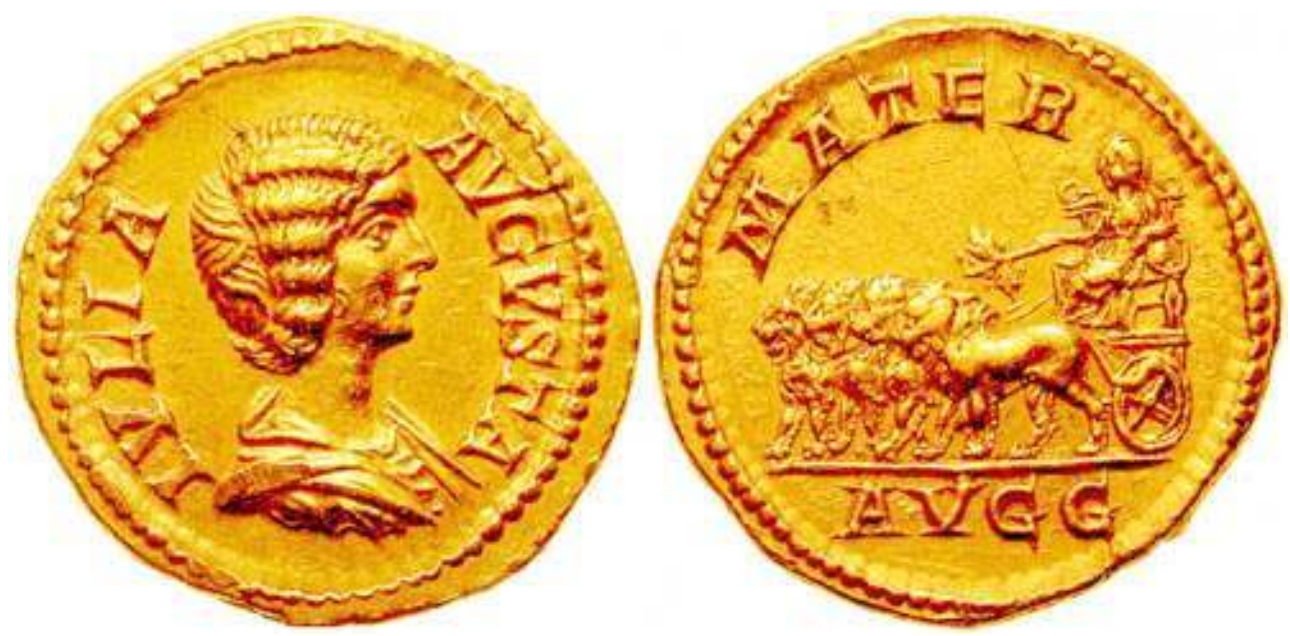

RIC, JuliaDomna, p. 168, 562. Droit : Buste drapée. IVLIA AVGVSTA. Revers : Cybèle tenant une branche et conduisant un quadrige tiré par des lions. MATER AVGG.

Fig. 6 : Iulia Domna, aureus, 196-211 ap. J.-C.
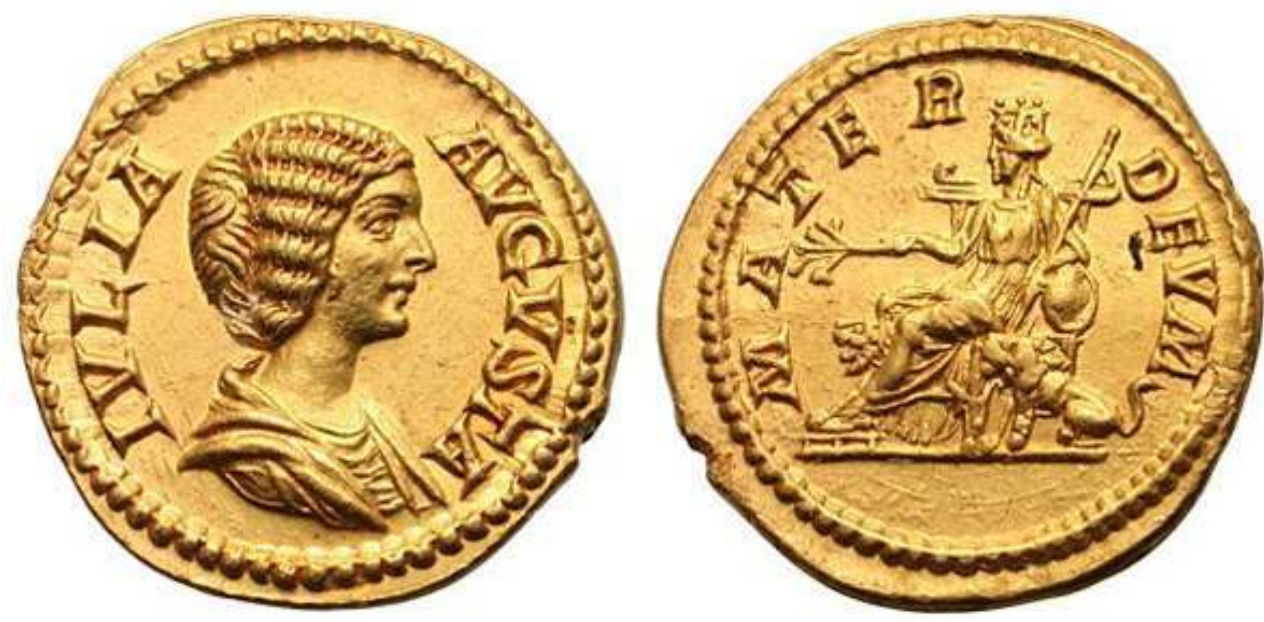

RIC, JuliaDomna, p. 169, 564. Droit : Buste drapé. IVLIA AVGVSTA. Revers : Cybèle, assise entre deux lions, tenant une branche dans la main droite et un sceptre reposant sur un tambour dans la main gauche. MATER DEVM. 
Fig. 7 : Iulia Domna, aureus, 211-217 ap. J.-C.
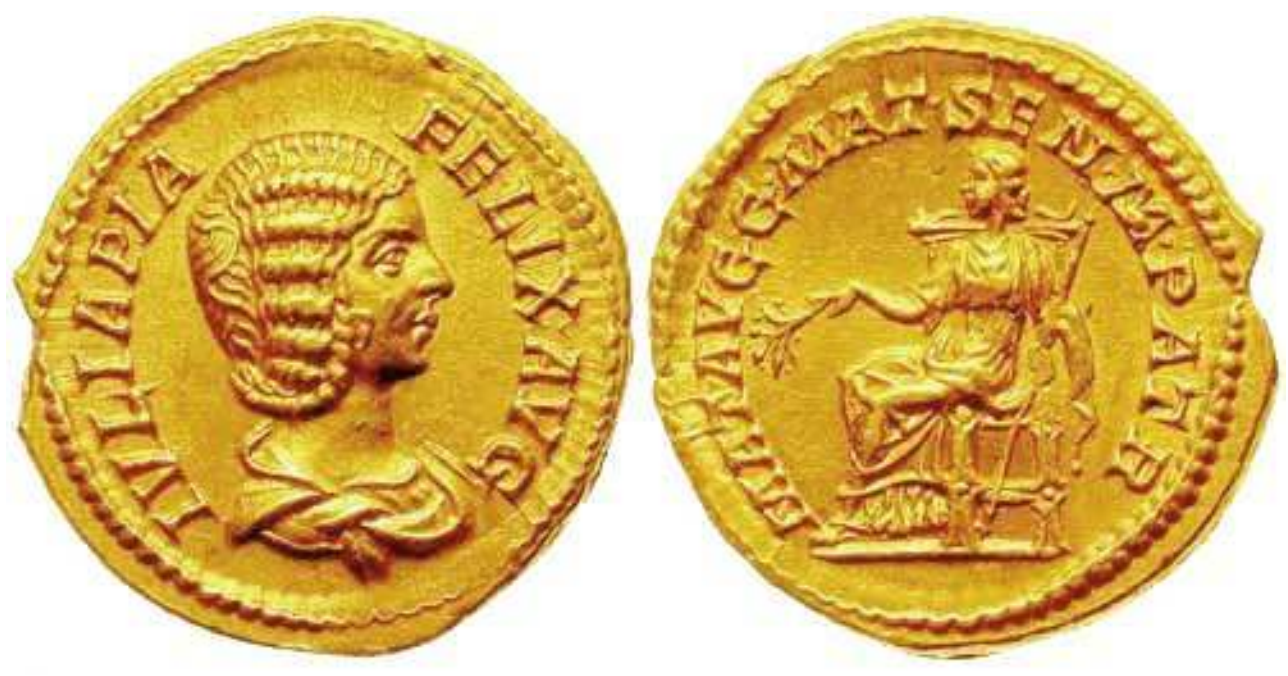

RIC, JuliaDomna, p. 273, 381. Droit : Buste drapé. IVLIA PIA FELIX AVG. Revers : Julia assise tenant une branche et un sceptre. MAT AVGG MAT SEN M PATR.

11 L'évolution chronologique de la propagande sévérienne se retrouve dans celle du système numismatique mis en place autour de Julia Domna et de la place de sa maternité dans l'État romain ${ }^{61}$. Pendant la guerre civile, l'impératrice reçoit le titre de mater castrorum ${ }^{62}$, déjà porté par Faustine la Jeune, titre qui étend sa bienveillance ${ }^{63}$, mais aussi son autorité maternelle à l'armée dans son ensemble ${ }^{64}$. Ses monnaies évoquent la fecunditas ${ }^{65}$ comme une vertu essentielle d'une impératrice associée à Vénus et Vesta ${ }^{66}$. C'est donc en tant que mère des futurs souverains que Julia Domna sert la propagande sévérienne des guerres civiles. La mise en scène de la famille de Septime Sévère est un argument en sa faveur dans la concurrence entre sénateurs. Une fois Septime Sévère au pouvoir, Julia Domna devient mater Augustorum et est représentée en Cybèle ${ }^{67}$ (fig. 5b). Ici, la maternité de l'impératrice prend donc un sens religieux qu'il faut rapprocher de ses origines syriennes. À la mort de Septime Sévère ${ }^{68}$, en 211 , elle reçoit les titres de Pia et Felix ${ }^{69}$, miroirs de ceux de Caracalla et symboles de sa position à la tête de l'État ${ }^{70}$. Après l'élimination de Géta, le lien iconographique entre Julia Domna et Cybèle permet de faire glisser la légende de mater Augg (ustorum) à mater deum, titre dont on ne sait plus s'il concerne Cybèle ou Julia Domna (fig. 6). Enfin, dans la dernière étape de cette évolution, Julia Domna s'attribue les titres de mater senatus et de mater patriae, pendant du titre masculin, pater patriae, en usage depuis Auguste (fig. 7). Par glissement de proche en proche, Julia Domna est devenue la mère de l'État romain. Le titre de mater senatus, quant à lui, fait une nouvelle fois écho au règne de Commode qui s'est proclamé pater senatus ${ }^{71}$. 
Fig. 8a : Iulia Maesa, antoninianus, 218-224.
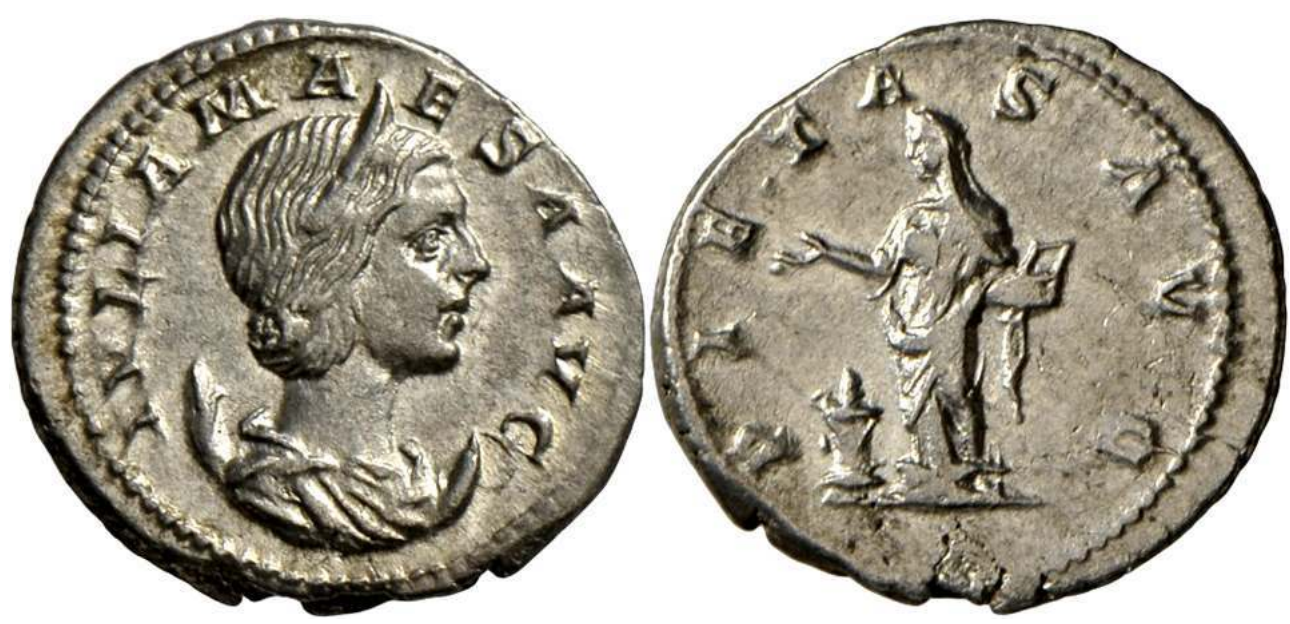

RIC, Iulia Maesa, p. 50, 264. Droit : Buste diadémé sur un croissant. IVLIA MAESA AVG. Revers : Pietas devant un autel. PIETAS AVG.

CoinArchives

Fig. 8b : Iulia Mamaea, dupondius,222-235.
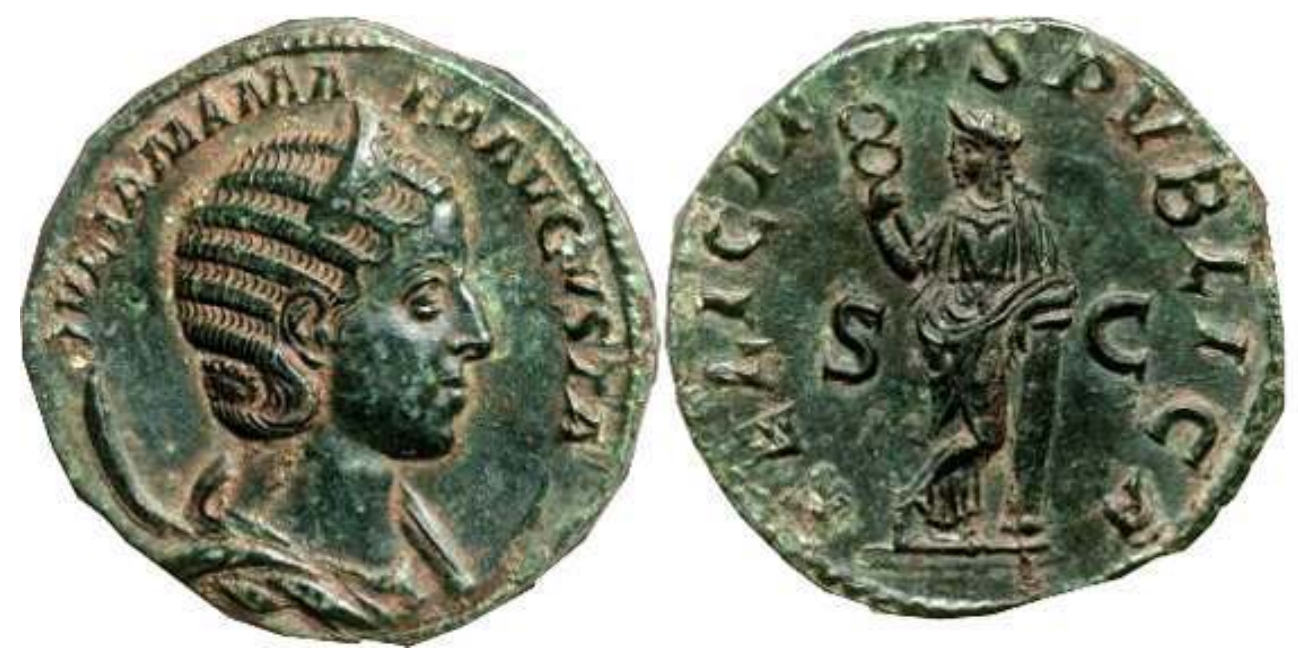

RIC, Iulia Mamaea, p. 125, 678. Droit : Buste diadémé sur un croissant. IVLIA MAMAEA AVGVSTA

Revers : Felicitas accoudée sur une colonne, jambes croisées, tenant un caducée. FELICITAS PVBLICA S. C.

CoinArchives

La construction de la maternité de Julia Domna comme élément de la structure étatique transfère le lien dynastique de la fiction antonine à la réalité sévérienne puisqu'elle met en avant, non pas le passé de la famille, mais son avenir et la promesse d'un retour de l'Âge d'Or. Signe de cette évolution, les portraits numismatiques de Julia Domna s'éloignent de plus en plus des canons antonins. Ses coiffures sont désormais ouvertement des perruques très imposantes ${ }^{72}$, son buste diadémé s'appuie sur un croissant de Lune. Pendant féminin de la couronne radiée des empereurs ${ }^{73}$, ce croissant symbolise le lien entre l'Augusta et l'éternité impériale et exprime clairement son statut de parèdre du prince, associé, lui, au Soleil. Julia Domna transmet ce type monétaire aux autres femmes de la dynastie dont une partie de la propagande repose sur le lien 
dynastique entre princesses syriennes (fig. 8a-8b). Les Sévères produisent donc une iconographie qui les rattache constamment à la famille antonine, mais permet également d'ancrer la famille sévérienne sur le trône en donnant à la maternité des impératrices un caractère sacré.

13 Assassiné en 217, Caracalla ne laisse pas d'héritier. Julia Domna meurt peu de temps après et tout porte à croire que la dynastie sévérienne est éteinte. Macrin, le nouvel empereur, doit cependant faire face à la branche syrienne de la famille. Une courte guerre civile, occasion de nouveaux exercices de propagande, en résulte. Le jeune cousin de Caracalla, Varius Avitus Bassianus, dit Élagabal, s'attache le soutien des soldats en se présentant comme son fils. Selon Dion Cassius (LXXIX, 32, 2), pour prouver sa filiation, « on porta Avitus, qu'on désignait déjà sous le nom de Marcus Aurelius Antoninus, autour des remparts et on exhiba des portraits de Caracalla quand il était enfant [...]». Le commentaire d'Hérodien $(\mathrm{V}, 4,4$.) sur l'événement est révélateur. Selon lui, les soldats sont convaincus de la ressemblance entre Caracalla et Élagabal, "parce que c'était ce qu'ils voulaient voir ». Il s'agit donc moins de montrer les portraits de Caracalla pour démontrer le lien filial que de donner une justification aux choix des soldats. La fiction généalogique ainsi entretenue est à nouveau validée par un consensus. Elle permet aux soldats de se battre par fidélité pour la mémoire de Marcus Aurelius Caracalla et non pour l'or que leur promet Marcus Aurelius Élagabal. Enfin, ce dernier prend le nom de Marcus Aurelius Antoninus, ce qui achève de l'identifier au prince assassiné ${ }^{74}$. L'accession au trône du jeune prêtre d'Émèse n'est donc pas une rupture, mais est présentée comme une restauration de la famille sévérienne, cette domus divina naturellement appelée à gouverner Rome.

14 La mort de Macrin et la victoire du parti sévérien ne suffisent pas à assurer le pouvoir d'Élagabal qui doit, pendant près d'un an, faire face à d'autres candidats à l'empire ${ }^{75}$. Sa propagande reprend alors le thème de la continuité dynastique dans sa titulature et ses portraits. Cependant, plutôt que de se conformer aux attentes des Romains et d'adopter l'apparence d'un Antonin, il se présente à eux dans sa tenue de grand prêtre du dieu dont il porte le nom. Selon Hérodien (V, 5, 3-4), « il portait les vêtements les plus chers, tissés de pourpre et d'or, et se parait de colliers et de bracelets. Sur sa tête, il portait une couronne en forme de tiare, brillante d'or et de pierres précieuses. L'effet produit était quelque part entre les habits sacrés des Phéniciens et la tenue luxueuse des Mèdes. » L' Histoire Auguste (Antoninus Heliogabalus, XXIII, 3-4) souligne l'incongruité de son apparence pour ses sujets: "Il portait des tuniques toutes en or, d'autres de pourpre, d'autres encore constellées de pierreries à la mode perse [...] Il avait des joyaux jusque sur ses chaussures, certains même gravés, ce qui suscitait l'hilarité générale [...] ». Loin des postures militaristes ou philosophiques adoptées par ses prédécesseurs, Élagabal conserve dans son apparence une magnificence qui impose le respect aux populations sémitiques, mais que les auteurs contemporains rejettent comme décadente et efféminée ${ }^{76}$. Conscient de la révolution idéologique que sa tenue impose, il cherche à préparer les Romains à cette apparence extravagante. Avant même d'être entré dans Rome, il fait donc réaliser un immense portrait de lui, en tenue sacerdotale, et ordonne qu'il soit exposé dans la Curie. De telle sorte que, selon Hérodien $(\mathrm{V}, 5,7)$ «Quand Antoninus arriva à Rome, dans le costume décrit précédemment, les Romains n'y virent rien d'inattendu, habitués qu'ils étaient au tableau. » Dans la capitale-même, le culte d'Élagabal est pratiqué depuis l'année 199 au moins ${ }^{77}$ et ce dieu n'est donc inconnu ni des sénateurs ni de la population. 


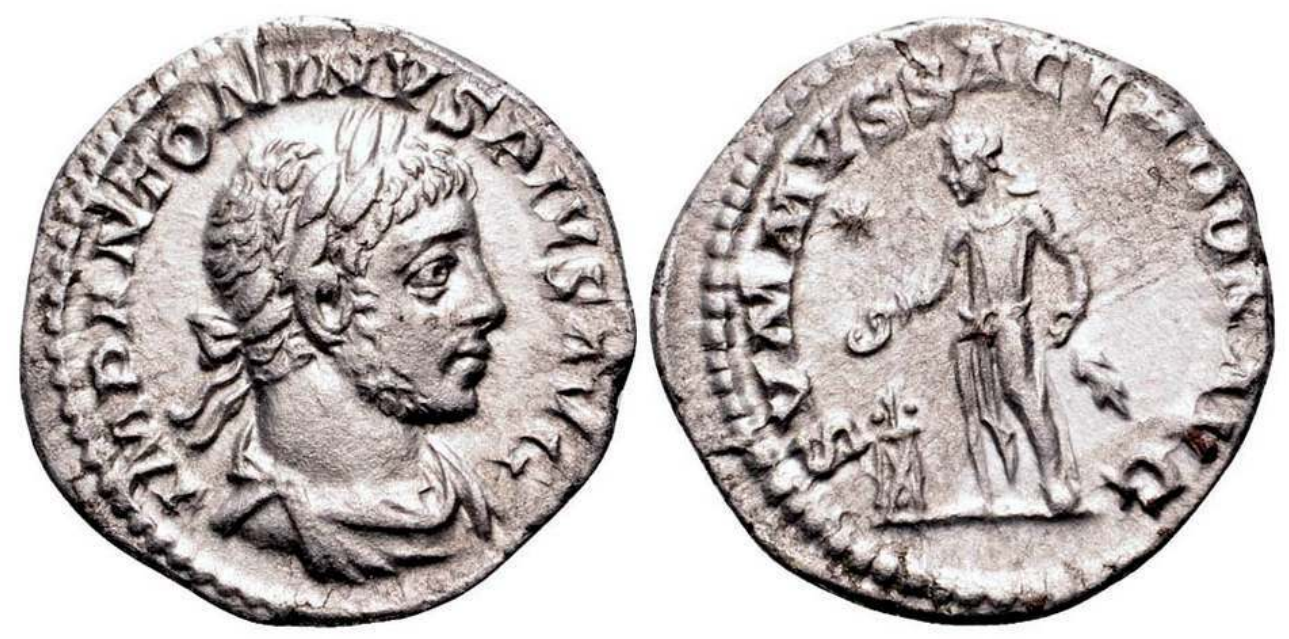

RIC, Elagabal, p. 38, 146b. Droit : Buste drapé et lauré. IMP ANTONINVS PIVS AVG. Revers : Elagabal debout devant un tripode, tenant une patère et une branche. SVMMVS SACERDOS.

CoinArchives

Fig. 10 : Elagabal, denarius, 218-222.
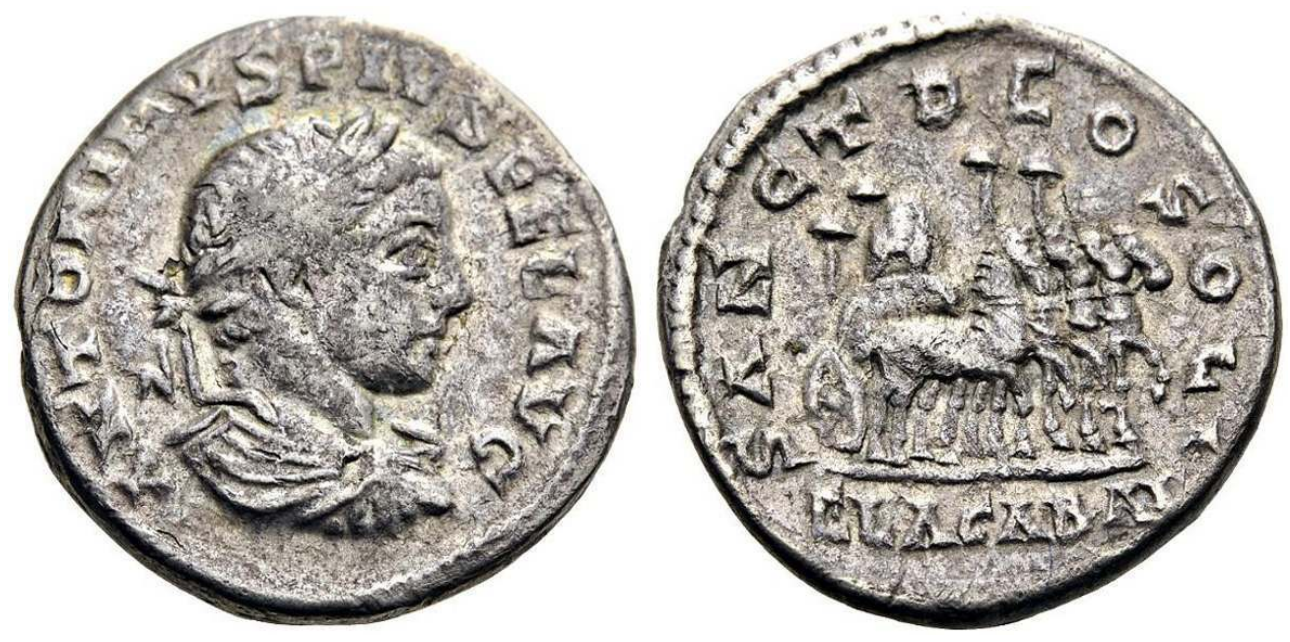

RIC, Elagabal, p. 43, 195. Droit : Buste drapé et lauré. ANTONINVS PIVS FEL AVG. Revers : Quadrige portant la pierre conique d'Émèse sur laquelle est gravée un aigle, entourée de quatre parasols. SANCT DEO SOLI ELAGABAL.

CoinArchives

Le jeune empereur innove donc avant tout en se présentant comme grand prêtre du dieu dont il apporte à Rome la pierre sacrée et les processions spectaculaires ${ }^{78}$. La production numismatique de son règne fait cohabiter l'iconographie classique d'un empereur portant cuirasse et couronne de laurier avec celle du grand prêtre sacrifiant au dieu d'Émèse (fig. 9). La tenue dans laquelle il se présente sur ces monnaies n'est cependant pas celle des prêtres syriens ${ }^{79}$, ni celle que décrivent les sources littéraires. Il s'agit d'un compromis entre l'origine syrienne de son sacerdoce et sa nouvelle place à la tête de la religion de l'État romain. Ce compromis se retrouve dans les présentations de l'activité sacerdotale d'Élagabal que ses monnaies montrent devant un autel, une patère à la main ${ }^{80}$ , dans des attitudes héritées de l'iconographie augustéenne ${ }^{81}$. Tout au long du règne 
cependant, des monnaies célèbrent le dieu Élagabal en empruntant à la numismatique proche-orientale des codes inaccessibles pour les populations de l'Occident romain (fig. 10). Elles figurent le bétyle d'Émèse, surmonté d'un aigle, tiré sur un quadrige, avec, en arrière-plan, quatre parasols qui symbolisent la souveraineté depuis l'époque achéménide. L'introduction de cette iconographie dans la numismatique romaine semble constituer une rupture par rapport à une propagande sévérienne dont on a indiqué la cohérence. Cette rupture est soulignée par les sources littéraires, toutes orientées par la réaction sénatoriale du règne suivant, qui s'en servent pour rejeter les prétentions d'Élagabal au nomen Antoninorum. Dion Cassius (LXXX, 1, 1), par exemple, présente le jeune empereur sous les noms d'«Avitus, également connu comme le Faux Antonin, ou l'Assyrien, ou Sardanapale, ou même Tiberinus (surnom qu'il reçut après avoir été tué et que son corps ait été jeté dans le Tibre)». En termes de propagande pourtant, son règne s'inscrit dans la continuité des précédents. L'emploi de la titulature antonine remonte au règne de Septime Sévère, tout comme l'expression numismatique du culte solaire ${ }^{82}$. Les sources littéraires reprochent donc à Élagabal ce qu'elles n'osent pas reprocher à la dynastie sévérienne dans son ensemble.

Fig. 11 : Sévère Alexandre, denarius, 221.
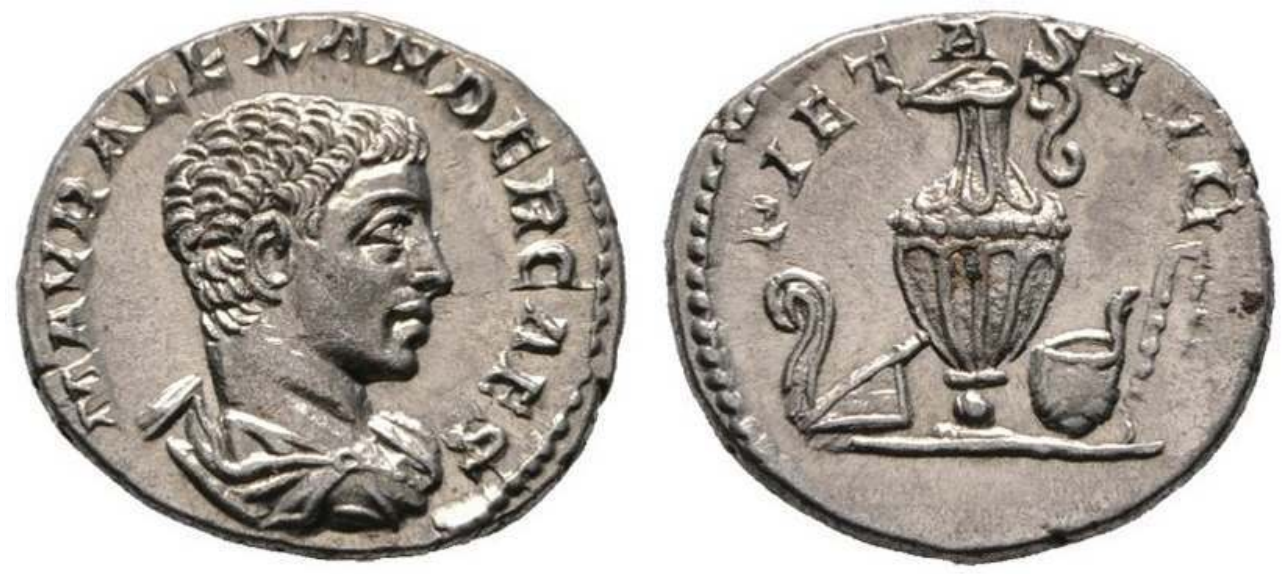

RIC, SeverusAlexander, p. 70, 3. Droit : Buste drapé. M. AVR ALEXANDER CAES. Revers : Lituus, secespita, capis, simpulum et aspergillum. PIETAS AVG. 
Fig. 12 : Sévère Alexandre, denarius, 233-235.
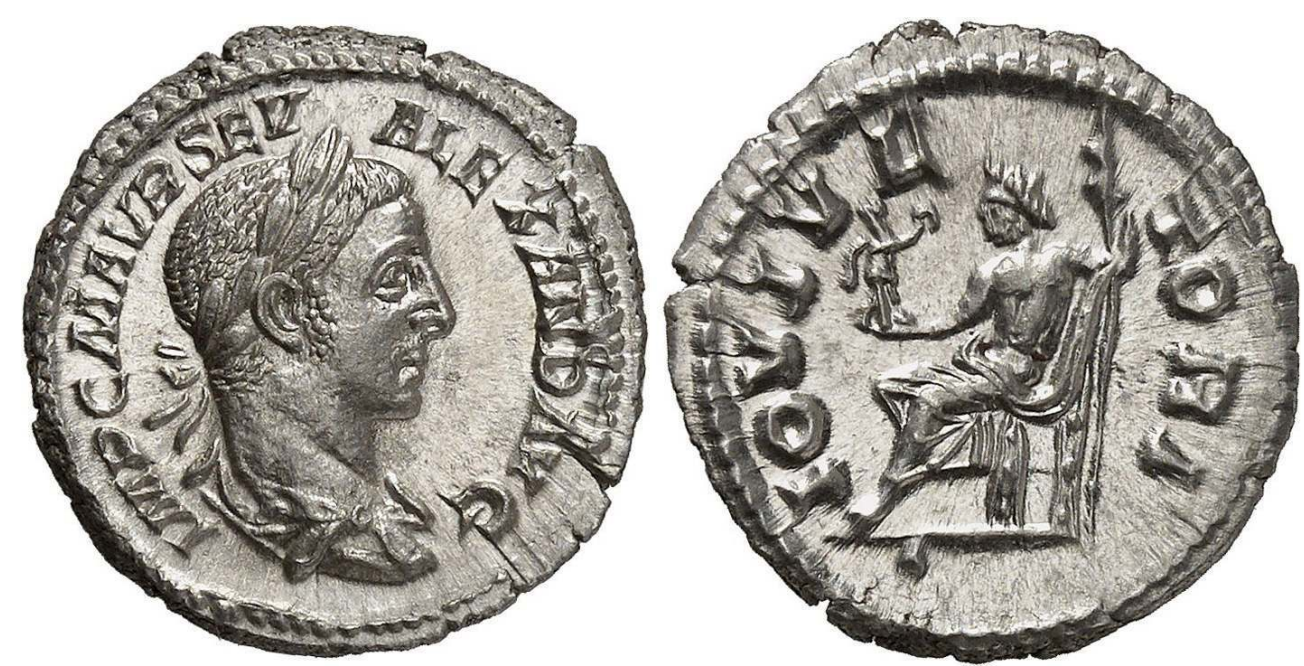

RIC, Severus Alexander, p. 82, 144. Droit : Buste drapé et lauré. IMP C M AVR SEV ALEXAND AVG. Revers : Jupiter assis, tenant la Victoire et un sceptre. IOVI VLTORI

16 Contrairement à celle de Caracalla, la mort d'Élagabal ne menace pas le pouvoir de sa famille. Sa succession est assurée par son cousin et fils adoptif, Sévère Alexandre. Durant leur court règne commun, les monnaies d'Alexandre mettent en avant une religion traditionnelle (fig. 11). Elles représentent les attributs des prêtres romains (patère, couteau, etc. ${ }^{83}$ et associent la pietas du jeune César à de pratiques résolument classiques. Les dieux qui apparaissent sur ses monnaies sont, de même, incontestablement romains. Jupiter apparaît sur $8 \%$ d'entre elles, contre $1,5 \%$ pour le règne d'Élagabal ; Mars en occupe $12 \%$, contre $2 \%$ chez Élagabal ; Sol, divinité liée au prince depuis Auguste, est représenté sur $8 \%$ des monnaies de Sévère Alexandre, donc plus souvent que sur celles d'Élagabal $(5 \%)^{84}$. Jupiter est volontiers doté de l'épiclèse Ultor, justicier, qui renvoie à la restauration, toute relative mais exploitée à des fins de propagande, de la religion traditionnelle romaine ${ }^{85}$ (fig. 12). Le dieu est aussi invoqué pour son action protectrice, sous ses épiclèses de Conservator et de Propugnator ${ }^{86}$. Sévère Alexandre se place donc sous la protection de Jupiter quand ses prédécesseurs lui avaient préféré des dieux originaires des provinces de l'empire, comme Sérapis ou Élagabal. Ce choix s'inscrit dans une propagande de retour à la norme antonine. Sévère Alexandre gouverne avec le Sénat, non contre lui, sous la protection de Jupiter Capitolin ${ }^{87}$. Selon une pratique désormais coutumière, le jeune prince prend le nom de Marcus Aurelius Severus Alexander qui lui permet de se rattacher à la fiction dynastique antonine, mais aussi au souvenir de Caracalla, ce nouvel Alexandre si apprécié des soldats. Encore une fois, les Sévères cherchent à perpétuer la fiction collective de la continuité dynastique.

En s'appropriant la propagande commodienne, les Sévères en valident les prémices et les conséquences logiques. Le plus noble des princes naît dans la maison impériale, domus Augusta, sacra ou divina, et cette hérédité lui donne droit à l'empire. Cette évolution, idéologique plus que fonctionnelle, impose aux empereurs du $\mathrm{III}^{\mathrm{e}}$ siècle un nouveau mode de légitimation. La victoire militaire qui fonde le titre d'Imperator ne suffit plus à s'assurer le pouvoir. Il faut désormais être lié par le sang à la famille des Antonins. Or ce lien familial ne peut être prouvé que par un certain «air de famille». C'est donc l'apparence du prince qui lui permet de démontrer sa légitimité. La propagande iconographique des 
monnaies sévériennes montre, mais ne démontre pas un lien dynastique inexistant et reconstruit à chaque génération. Elle peut convaincre, mais, surtout, elle autorise celui qui la reçoit à se convaincre de la vérité de l'image et de ses implications politiques.

Mise en place par Septime Sévère dans le contexte des guerres civiles et de la concurrence généalogique avec Clodius Albinus, la fiction de la parenté antonine est d'autant plus acceptable qu'elle fournit à l'Empire une stabilité qui lui fait en réalité défaut. La généalogie fictive des Sévères simplifie la compréhension de la succession impériale. Elle est plus acceptable puisqu'elle se conforme à la faveur que les dieux accordent au peuple romain dont l'Empire doit être éternel. Dans ce sens, la mise en scène du lien dynastique permet de montrer une fiction qui s'avère, pour ses contemporains, plus cohérente, donc plus légitime, que la réalité. Au fantasme du choix du meilleur promulguée par les Antonins succède celui d'une hérédité impériale, intangible, invisible, mais observable, pour celui qui le veut, dans les monnaies que les citoyens de l'Empire manipulent tous les jours et avec lesquelles l'empereur paie ses soldats ${ }^{88}$. En affirmant leur appartenance à la dynastie antonine, Septime Sévère et sa famille mettent en avant l'immuabilité du pouvoir impérial. En montrant qu'un Antonin est toujours sur le trône, ils démontrent l'éternité de Rome. La mise en scène de la continuité dynastique n'est pas, au $\mathrm{II}^{\mathrm{e}}$ siècle, une supercherie, mais une nécessité. De proche en proche, elle fait remonter la famille régnante jusqu'à Auguste, donc jusqu'à la maison d'Énée, dont les poètes avaient promis qu'elle régnerait toujours.

\section{BIBLIOGRAPHIE}

\section{Sources}

Cassius Dion, Histoire romaine, trad. E. Cary, Londres, 1927.

Hérodien, Histoire des empereurs romains, trad. D. Roques, Paris, 2004.

\section{Bibliographie}

Alexandridis A. (2004), Die Frauen des Römischen Kaiserhauses. Eine Untersuchung ihrer bildlichen Darstellung von Livia bis Iulia Domna, Mayence.

Ando C. (2012), Imperial Rome AD 193 to 284. The Critical Century, Édimbourg.

Baharal D. (1996), Victory of Propaganda. The Dynastic Aspect of the Imperial Propaganda of the Severi: the Literary and Archeological Evidence AD 193-135, Oxford.

Balty J. (1972), « Notes d'iconographie sévérienne », AC 41, Bruxelles, p. 623-642.

Bastien P. (1992), Le buste monétaire des empereurs romains, Wetteren.

Birley A. R. (1988), The African Emperor. Septimius Severus, Londres.

Callu J.-P. (2000), « Pia Felix », RN 155, p. 189-207. 
Catalli F. (2005), «L'uso dei ritratti nella moneta romana », dans Catalli F. et Manconi D. éd., Le immagini del potere. Il potere delle immagini. L'uso del ritratto ufficiale nel mondo romano da Cesare ai Severi, Pérouse, p. 57-66.

Chausson F. (1995), « Vel Iovi vel Soli : quatre études autour de la Vigna Barberini (191-354) », MEFRA 107, p. 661-765. DOI : 10.3406/mefr.1995.1906

- (1998), «Les lignages mythiques dans quelques revendications généalogiques sous l'empire romain », dans Auger D. et Saïd S. éd., Généalogies mythiques, Nanterre, p. 395-417.

- (2007), « Variétés généalogiques. IV - Cohésion, collusions, collisions : une autre dynastie antonine ", dans Bonamente G. et Brandt H. éd., Historiae Augustae Colloquium Bambergense, n. s. X (Bamberg, 2005), Bari, p. 153-154.

Cheung A. (1998), « The political significance of Roman imperial coin types », Shweizer Münzblätter 48-49, p. 53-61.

Clauss M. (2001), Kaiser und Gott : Herrscherkult im römischen Reich, München.

Daguet-Gagey A. (2000), Septime Sévère. Rome, l'Afrique et l'Orient, Paris.

Desnier J.-L. (1993), « Omnia et realia. Naissance de l'Urbs sacra sévérienne (193-204 ap. J.-C.) », MEFRA 105, nº 2, p. 547-620. DOI : 10.3406/mefr.1993.1814

Dirven L. (2007), « The emperor's new clothes: a note on Elagabalus'priestly dress », dans Greisiger L. et Vashalomidze S. éd., Die Christliche Orient und seine Umwelt, Wiesbaden, p. 21-36. Duncan-Jones R. (2005), «Implications of Roman coinage: debates and differences », Klio 87, p. 459-487.

Hekster O. (2007), « The Roman army and propaganda », dans Erdkamp P. éd., A Companion to the Roman Army, Malden, p. 339-358.

Gnecchi F. (1902), I medaglioni Romani, vol. II, Milan.

Grenier J.-C. (2007), « Sarapis et le glaive de Caracalla », dans Sauzeau P. et Van Compernolle T. éd., Les Armes de l'Antiquité. De la technique à l'imaginaire, p. 407-420.

Icks M. (2008), Images of Elagabalus, Nimègue.

- (2012), The Crimes of Elagabalus. The Life and Legacy of Rome's Decadent Boy Emperor, Harvard.

Levick B. (2007), Julia Domna, Syrian Empress, New York.

Lichtenberger A. (2011), Severus Pius Augustus. Studien zur sakralen Repräsentation und Rezeption der Herrschaft des Septimius Severus und seiner Familie (193-211 n. Ch.), Leiden.

Lo Cascio E. (2008), « The age of the Severans », Bowman A., Garnsey P. et Cameron A. éd., The Cambridge ancient history, vol. XII, The crisis of empire, Cambridge, p. 137-155.

Manders E. (2012), Coining Images of Power. Patterns in the Representation of Roman Emperors on Imperial Coinage A.D. 193-284, Leiden.

Morelli A. L. (2009), Madri di uomini e di dèi. La rappresentazione della maternità attraverso la documentazione numismatica di epoca romana, Bologne.

Norena C. (2001), « The communications of the emperor's virtues », JRS 91, p. 146-168.

- (2011), Imperial Ideals in the Roman West: Representation, Circulation, Power, New York.

Pflaum H.-G. (1961), « Les gendres de Marc Aurèle », JS 1, p. 28-41. 
Rowan C. (2009), «Becoming Jupiter: Severus Alexander, the temple of Jupiter Ultor, and Jovian iconography on Roman imperial coinage », AJN 21, New York, p. 123-150.

- (2011), « The public image of the Severan women », PBSR 79, p. 241-273.

- (2012), Under Divine Auspices. Divine Ideology and the Visualisation of Imperial Power in the Severan Period, New York.

Sapelli M. (2005), « La ritrattistica ufficiale romana da Cesare ai Severi », dans Catalli F. et Manconi D. éd., Le immagini del potere. Il potere delle immagini. L'uso del ritratto ufficiale nel mondo romano da Cesare ai Severi, Pérouse, p. 33-48.

Scheithauer A. (1988), « Super omens retro principes. Zur inoffiziellen Titulatur römischer Kaiser », ZPE 72, p. 155-276.

Soechting D. (1972), Die Porträts des Septimius Severus, Bonn.

Speidel M. A. (2012), « Faustina - mater castrorum. Ein Beitrag zur Religionsgeschichte », Tyche 27, p. 127-152.

Veyne P. (2002a), «Lisibilité des images, propagande et apparat monarchique dans l'Empire romain », RH 621, p. 3-30.

- (2002b) «Qu'était-ce qu'un empereur romain ? Dieu parce qu'empereur », Diogène 199, p. 3-25.

\section{NOTES}

\section{Hérodien, I, 5, 5.}

2. Scheithauer 1988. Une inscription de Numidie qualifie Commode de nobilissimus omnium et felicissimus principum (CIL, VIII, $10307=$ ILS, 397).

3. Sous le Haut-Empire, ces vertus principales sont Aequitas, Clementia, Indulgentia, Iustitia, Liberalitas, Munificentia, Patientia, Pietas, Providentia, Pudicitia, et Virtus. Norena 2001, p. 155.

4. Baharal 1996, p. 21.

5. CIL, VIII, 9317.

6. Dion Cassius, LXXVII, $9,4$.

7. Birley 1988, p. 117-118.

8. Pflaum 1961.

9. Veyne 2002a, p. 5.

10. Cheung 1998, p. 58.

11. Icks 2012, p. 95.

12. Selon Duncan-Jones, les monnaies se diffusent mal d'une région à l'autre de l'empire. Il en déduit qu'elles ne sont pas produites dans un but de propagande. C'est confondre intentions et résultats. La monnaie reste le meilleur medium disponible pour les empereurs romains : Duncan-Jones 2005.

13. Hekster 2007, p. 340.

14. Manders 2012, p. 28

15. Veyne 2002b, p. 6.

16. Desnier 1993, p. 548. 
17. Baharal 1996, p. 9.

18. Veyne 2002 b, p. 7.

19. Desnier 1993, p. 586.

20. Rowan 2012, p. 33.

21. Hérodien, II, 3, 4 .

22. On disait de Marc Aurèle lui-même qu'il descendait de Numa. Il était, en tout cas, un descendant de Pompée. Voir Chausson 1998, p. 400.

23. Histoire Auguste, Helvius Pertinax, IV, 10.

24. Chausson 2007, p. 153-154.

25. Soechting 1972, p. 14.

26. Ando 2012, p. 33.

27. Daguet-Gagey 2000, p. 336.

28. Hekster 2007, p. 349.

29. Cheung 1998, p. 54.

30. Rowan 2012, p. 13.

31. On connaît 815 types monétaires pour la seule période 198-217. Manders 2012, p. 226.

32. AE, 1973, 226 (Castrum Novum) : «Imp(erator) Caesar / L(ucius) Septimius Severus / Pius Pertinax Aug(ustus) (...) ».

33. Dion Cassius, LXXV, $4,1$.

34. Dion Cassius, LXXVI, 7,4 .

35. Daguet-Gagey 2000, p. 255.

36. Balty 1972, p. 623.

37. Bastien 1992, p. 27.

38. Sapelli 2005, p. 46.

39. RIC, Marcus Aurelius, p 243, 388.

40. RIC, Caracalla, p. 212, 3.

41. RIC, Marcus Aurelius, p. 263, 604.

42. Art Walters Museum, $n^{\circ}$ 59, 3.

43. Gnecchi 1902, tav. 60, 7, tav. 74, 9, tav. 93, 10 et tav. 95, 2.

44. Rowan 2011, p. 253.

45. RIC, Severus, p. 167, 548.

46. RIC, Marcus Aurelius, p. 270, 704.

47. Soechting 1972, p. 50.

48. Balty 1972, p. 624.

49. Birley 1988, p. 138.

50. De retour dans la cité en 215 , Caracalla offre à Sérapis l'épée avec laquelle il a tué Géta. Grenier 2007, p. 407-420.

51. RIC, Severus, p. 168, 559.

52. Bastien 1992, p. 603.

53. RIC, Caracalla, p. 220, 52. 
54. Norena 2001, p. 135.

55. RIC, Severus, p. 130, 312.

56. Catalli 2005, p. 57.

57. RIC, Severus, p. 114, 174.

58. RIC, Marcus Aurelius, p. 263, 604.

59. Lo Cascio 2008, p. 140.

60. Clauss 2001, p. 158.

61. Morelli 2009, p. 127-144.

62. RIC, Julia Domna, p. 168, 563a et 563b, p. 169, 568.

63. Le titre de Mater castrorum a une dimension religieuse. Voir Speidel 2012.

64. Alexandridis 2004, p. 26.

65. RIC Julia Domna, p. 165, 534.

66. RIC Julia Domna, p. 165, 535 à 538.

67. Une statue dor de Julia Domna installée au Parthénon associait également l'impératrice au culte d'Athéna, mais cette association n'a pas laissé de trace numismatique. Lichtenberger 2011, p. 327.

68. Rowan 2011, p. 254.

69. RIC, Julia Domna, p. 274, 393.

70. Callu 2000, p. 196.

71. RIC, Commodus, p. 383, 156 et 157.

72. RIC, Julia Domna, p. 273, 379 et p. 274, 388a.

73. Bastien 1992, p. 645.

74. Icks 2008, p. 56.

75. Ibid., p. 59.

76. Icks 2012, p. 98-100.

77. Chausson 1995, p. 691.

78. Ibid., p. 713.

79. Dirven 2007, p. 25.

80. Icks 2008, p. 109.

81. Dirven 2007, p. 30.

82. RIC, Caracalla, p. 218, 39a et 39b.

83. Icks 2012, p. 79.

84. Manders 2012, p. 103, p. 116 et p. 124.

85. Rowan 2009, p. 129.

86. Ibid., p. 137.

87. Clauss 2001, p. 181.

88. Manders 2012, p. 64. 


\section{RÉSUMÉS}

Comment une dynastie peut-elle en remplacer une autre ? La question est posée chaque fois que la direction de l'empire romain passe d'une famille à une autre. Au-delà de la conquête du pouvoir lors des guerres civiles, il importe au nouvel empereur de faire accepter le règne de sa famille. Les monnaies des Sévères permettent d'étudier les stratégies mises en œuvre pour réaliser cette transition dynastique. La légitimation de la famille sévérienne passe par la mise en scène du lien fictif avec la dynastie antonine, mais aussi la sacralisation de la maternité de Iula Domna et la revendication d'une continuité dynastique de Septime Sévère à Sévère Alexandre. L'iconographie et les textes des monnaies sévériennes procèdent donc d'un double message, celui de la continuité antonine et de l'établissement d'un nouveau règne. D'émission monétaire en émission monétaire, la famille sévérienne se construit l'image d'une dynastie dont la continuité est, en soi, facteur de légitimité.

How does an imperial dynasty replace another? Every Roman civil war creates a new emperor who then has to ensure the legitimacy of his entire family to rule. The Severan coinage provides us with a means to study the strategies used by that family to present itself as the ruling dynasty rather than as a newcomers and usurpers. That process implies the publicity of the Antonine line's continuation through the fictional adoption of Severus by Marcus Aurelius. The legitimacy of that renewed Antonine dynasty is then transferred to the Severan family through the divine maternity of Iulia Domna and the perpetuation of the ruling family. The Severans use their coinage to convey a double set of messages; the Antonines still rule the Empire and the Severans form the imperial dynasty.

INDEX

Mots-clés : Sévères, numismatique, dynastie, propagande

Keywords : Severan dynasty, numismatic, propaganda

\section{AUTEUR}

\section{VINCENT N'GUYEN-VAN}

ANHIMA - UMR 8210 